\title{
Gender and Place of Settlement as Predictors of Perceived Social Support, PTSD, and Insomnia among Internally Displaced Adolescents in North-East Nigeria
}

\author{
Onyekachi Prince David ${ }^{1, *(1)}$, Jesper Dammeyer ${ }^{1}$ and Ismaila Yakubu ${ }^{2}$ \\ 1 Department of Psychology, University of Copenhagen, 1353 Copenhagen K, Denmark; \\ jesper.dammeyer@psy.ku.dk \\ 2 Department of Psychology, Faculty of Social Sciences, Plateau State University, Bokkos PMB 2012, Nigeria; \\ ismailayaku-bu9@gmail.com \\ * Correspondence: onyekadavid@yahoo.co.uk
}

\section{check for} updates

Citation: David, Onyekachi Prince, Jesper Dammeyer, and Ismaila Yakubu. 2021. Gender and Place of Settlement as Predictors of Perceived Social Support, PTSD, and Insomnia among Internally Displaced Adolescents in North-East Nigeria. Social Sciences 10: 428. https:// doi.org/10.3390/socsci10110428

Academic Editors: Andrea C

Simonelli and Heather R. Croshaw

Received: 11 July 2021

Accepted: 2 November 2021

Published: 7 November 2021

Publisher's Note: MDPI stays neutral with regard to jurisdictional claims in published maps and institutional affiliations.

Copyright: (c) 2021 by the authors. Licensee MDPI, Basel, Switzerland. This article is an open access article distributed under the terms and conditions of the Creative Commons Attribution (CC BY) license (https:/ / creativecommons.org/licenses/by/ $4.0 /)$.

\begin{abstract}
Previous research has shown that gender affects social support and post-traumatic stress disorders (PTSD). The present study explores the main and interaction effects of gender and place of settlement on social support, PTSD symptoms, and insomnia in internally displaced adolescents (IDAs) in North-east of Nigeria. A stratified sampling method was used to select 109 participants from IDAs living in the camp, while 27 additional IDAs were purposively recruited from those living in the host community. Participants completed measures of Harvard Trauma Questionnaire Part-II, Insomnia Severity Index, and Crisis Support. No significant effects of gender on perceived social support, PTSDs, and insomnia were observed. Place of settlement had a significant effect on social support, with IDAs living in the camp having a higher mean score, while place of settlement had no significant effects on PTSD and insomnia. A significant interaction effect of gender and place of settlements on insomnia was found, with males living in the community having a higher mean score than their female counterparts, as well as both males and females in the camp. In conclusion, there is a need to understand male IDAs who reside in non-camp settings better, including the nature of their challenges, the outcomes they desire, and the limitations they experienced.
\end{abstract}

Keywords: gender; place of settlement; social support; PTSD; insomnia; internally displaced adolescents

\section{Introduction}

The ongoing insurgency of Boko Haram in the north-eastern region of Nigeria has displaced over 2.1 million people from their homes, and children and adolescents constitute the overwhelming majority $(60 \%)$ of those internally displaced (International Organization for Migration (IOM 2021)). Evidence shows that children and adolescents are more vulnerable to posttraumatic stress disorders (PTSD; Stupar et al. 2021). PTSD is known as one of the most common mental health problems triggered by experiencing or witnessing traumatic events including sexual violence, threatened death, and loss of livelihood and family members. Consequently, Yatham et al. (2018) reported higher prevalence rates of PTSD, ranging from 0.2-89\%, among displaced children and adolescents living in low- and middle-income countries (LMICs). Additionally, in LMICs, internal displacement is usually protracted, and most of the displaced persons often live in poor resource settlements where social vulnerability and lack of adequate infrastructure, along with uncertainty of the future, can act to compound the already raised risk of PTSD.

Unsurprisingly, the overwhelming majority of internally displaced persons (IDPs) in north-eastern Nigeria have been severely traumatized by the insurgent attacks of Boko Haram (Raji et al. 2021; Sheikh et al. 2016). This could make them more vulnerable to other mental health problems such as sleep disturbance, also known as insomnia. Insomnia is a common problem in those exposed to armed-conflict and trauma (Lies et al. 
2021). For instance, insomnia is reported to be associated with stressful and traumatic experiences (Basishvili et al. 2012), and is a frequent symptom of PTSD. Likewise, over 90\% of individuals with PTSD report insomnia (Seelig et al. 2010). Moreover, Kubzansky et al. (2014) suggested that the higher rate of insomnia in persons with PTSD might increase their risk of developing physical health problems such as obesity. However, studies on insomnia in internally displaced persons are limited, especially among the adolescent group, which constitutes over $60 \%$ of all IDPs in north-eastern Nigeria (IOM 2021). The few existing studies from Russia, North Korea, and Australia have reported a high prevalence in displaced populations, with incidence of 44\% (Basishvili et al. 2012), 38\% (Lee et al. 2016), and 32\% (Bruck et al. 2020). Therefore, there is a clear need to study insomnia as an independent disorder within internally displaced adolescents (IDAs) in Nigeria.

\subsection{Gender}

According to the World Health Organization (WHO 2004), gender-sensitive health research is necessary because gender is among the key factors, alongside other social determinants, that explains mental health risks. In view of this, researchers need to consider gender if they are to provide policy-makers and practitioners with appropriate evidence. Accordingly, existing research demonstrates the importance of gender as a determinant of mental health indicators, including PTSD. For example, in general population studies, females have a two to three time's higher risk of developing PTSD compared to males (Olff 2017). Studies in the southwestern part of Uganda (Ainamani et al. 2020) and in western India females had, overall higher PTSD scores compared to males (John et al. 2007; Kessler et al. 1995; Kumar et al. 2007). Females seem to carry a higher burden of PTSD than males in conflict-affected settings (Ainamani et al. 2020; Bronstein and Montgomery 2011; Farhood and Dimassi 2012; Steel et al. 2009). For example, in trauma victims from Jammu and Kashmir, in the northern state of India, the lifetime prevalence of PTSD was 10-12\% in female and 5-6\% in male participants (Charak et al. 2014). Furthermore, females reported significantly more symptoms of PTSD compared to males in Darfur (Hamid and Musa 2010), and in a similar study by Ayazi et al. (2014) in South Sudan, females were found to have a risk factor for having PTSD. However, the findings on gender differences are not conclusive. De Jong et al. (2001) in Cambodia, Algeria, and Gaza, did not consistently find gender differences in their study. Where females reported more PTSD symptoms than males in Cambodia and Algeria, males reported more PTSD symptoms than females in Gaza. Other similar studies have reported no differences between the presence of PTSD in males and females (Taha and Sijbrandij 2021; Thabet and Thabet 2017).

In terms of insomnia, previous and recent studies, e.g., Seelig et al. (2010), Polyné et al. (2021), and Zeng et al. (2020), reported a higher level of insomnia for females than for males. Conversely, other similar studies, e.g., López-Torres Hidalgo et al. (2012), found a higher level of insomnia for males than for females. However, in the study of Kolakowsky-Hayner et al. (2021), the males and females did not differ significantly on the level of insomnia (overall sleep quality). Given this, the aforementioned studies on gender differences are inconsistent. Therefore, exploring gender differences in PTSD and insomnia among IDAs in Nigeria is warranted.

\subsection{Place of Settlement}

Place of settlement, such as living in an organized camp or in local communities, might explain the differences in social support and risk of PTSD. Usually, IDPs move from one location to another for several reasons, including their perceived greater access of public services, livelihood opportunities, and physical security. Likewise, the Integrated Regional Information Network (IRIN 2013) noted that, sometimes camps do not exist cannot be established, or the conditions are too bad in the camps, and therefore IDPs decide on alternatives. In many cases, it may be easier for IDPs to settle down and start a new life outside the camps, which might explain why about $61 \%$ of IDPs reported living in non-camp settings in Nigeria (IOM 2018). It might be assumed that IDPs outside camps 
are less in need of protection and assistance because their families, neighbors, or friends are caring for them, or that they have somehow found a solution on their own. However, while IDPs living in camps are greatly affected by their relations with their hosts in the communities, non-camp IDPs are mostly tangled with their hosts; equally, they may be unable to access or rely on other support, such as that from aid groups. For example, in one analysis of IDPs trends by the Internal Displacement Monitoring Centre, it was found that, in some of the countries reviewed, most of the IDPs in non-camp settings received no assistance beyond that provided by their host communities and families (IDMC 2011). Similar findings were reported by the Inter-Agency Standing Committee (IASC 1993) in countries where IDPs were living in both gathered (camp) and dispersed (non-camp) settings; national authorities and humanitarian actors were twice as likely to provide assistance and protection to IDPs in camp settings as to those in non-camp settings. However, the Internal Displacement Monitoring Centre suggests that IDPs' susceptibility is contingent on their place of settlement (IDMC 2008). Furthermore, a Kenyan study showed that, despite the progress in assisting IDPs, those in the camps were simply more visible and easier to target with humanitarian support and livelihood recovery assistance (Kamungi 2013).

Altogether, there is a dearth of studies comparing IDAs in the camps and those in non-camp settings, with regard to their support, insomnia, and PTSD symptoms. Therefore, whether the social support, insomnia, and PTSD symptoms of IDAs differ between those living in camps and IDAs in a non-camp in Nigeria is unknown.

\subsection{Social Support}

According to Jenchura et al. (2017), social support is generally perceived differently between males and females. For example, in a study of non-displaced populations, Lee and Goldstein (2016) found gender differences for social support, such that females reported more social support than their male counterparts, whereas, no gender differences were found in the study of Pettus-Davis et al. (2018). Nevertheless, studies from displaced populations are overall conflicting. For example, in Ethiopia, male IDPs, as compared to females, reported a higher level of insomnia (Araya et al. 2007). Conversely, in the study of Llabre and Hadi (1997), among 151 Kuwaiti girls and boys exposed to trauma during the Gulf War crisis found that the boys had lower social support than the girls. Other similar studies have shown no gender difference of social support (Betancourt et al. 2012; Akiyama et al. 2013).

Furthermore, Thoits (2011) documented several buffering mechanisms of social support to mental health in an extensive review. Likewise, the studies of DeLong (2012) and Van Droogenbroeck et al. (2018) suggested that social support contributes to gender disparities in mental health problems, and that inequality of support exposes females to chronic stressors, which comprised of a higher degree of poverty and hunger compared to males. Accordingly, studies have found that the impact of social support on mental health problems differs by gender. For instance, in a population study, Schraedley et al. (1999) reported a greater effect of social support on mental health for girls than for boys. Likewise, a study among adult earthquake survivors in Peru showed that females who scored low on perceived social support reported higher symptoms of PTSD (Cairo et al. 2010). There are a number of studies showing gender differences of social support in war-affected populations; however, such studies' findings are conflicting. This issue of gender and social support needs further investigation. Therefore, exploring the effect of gender on IDAs' social support in Nigeria is warranted.

\subsection{Interaction Effects}

Of further concern, there is a dearth of studies pertaining the interaction effects of gender and place of settlement (camp versus non-camp) on mental health indicators (e.g., PTSD and insomnia); despite the fact that IDPs' place of settlement may worsen their vulnerability to mental health problems (IDMC 2008). For instance, the Women's 
Commission for Refugee Women and Children (WCRWC 2006) report indicated that females in displaced camps are easy targets for abuse and discrimination, especially when they are separated from normal support systems, which might have a detrimental effect on their mental health. Additionally, there may be interaction effects between gender and place of settlement on mental health indicators. Given the limited evidence to date, our study fills this gap by exploring the interaction effect between gender and place of settlement on social support, insomnia, and PTSD symptoms. However, to the best of our knowledge, this is the first study to examine the interaction effect between gender and place of settlement on social support, insomnia, and PTSD symptoms, especially in displaced adolescents.

\section{The Present Study}

As there are a number of studies showing gender differences on mental health problems in war-affected children and adolescents, the present study builds and extends on previous research by investigating the effects of gender and place of settlement on social support, insomnia, and PTSD symptoms in children and adolescents who were internally displaced in the north-east of Nigeria. Hence, the present study seeks to find answers to the following research questions: Firstly, whether gender and place of settlement (camp versus non-camp) have an effect on perceived social support, insomnia, and PTSD symptoms. However, based on the state of literature concerning gender, we expected a significant effect of gender on perceived social support, insomnia, and PTSD symptoms, given that nothing is known regarding the interaction effect between gender and place of settlement on social support, insomnia, and PTSD symptoms. Therefore, the second research question considers if a significant interaction effect exists between gender and place of settlement (camp versus non-camp) on social support, insomnia, and PTSD symptoms.

\section{Materials and Methods}

\subsection{Participants and Sampling Strategy}

The study was designed as a cross-sectional survey, and a total of $N=136$ IDAs were sampled with an age range of $10-21$ years and a mean of 16.5 years $(S D=2.45)$. The study employed two types of sampling strategies, which involved a stratified sample of 109 IDAs from the Stefanos Foundation camp. In addition to this, 27 participants were purposively sampled from the K-Vom community IDAs settlement in the Plateau State.

As seen in Table 1, out of the 136 participants, more than half were female $(60.3 \%)$ and the majority of participants lived in the camp $(80.1 \%)$ and were single $(54.4 \%)$ and Christians $(92.7 \%)$.

Table 1. Sociodemographic characteristics $(N=136)$.

\begin{tabular}{ccc}
\hline Characteristics & $N$ & $\%$ \\
\hline Age Group & 38 & 27.9 \\
Younger adolescent & 98 & 72.1 \\
Older adolescent & 54 & 39.7 \\
Gender & 82 & 60.3 \\
Male & 1 & 0.7 \\
Female & 126 & 92.7 \\
Religion & 9 & 6.6 \\
None & & 54.4 \\
Christianity & 74 & 42.6 \\
Islam & 58 & 2.9 \\
Marital status & 4 & \\
Single & & \\
Married & &
\end{tabular}


Table 1. Cont.

\begin{tabular}{ccc}
\hline Characteristics & $\boldsymbol{N}$ & $\%$ \\
\hline Educational level & 51 & 37.5 \\
Non formal & 66 & 48.5 \\
Primary & 17 & 12.5 \\
Secondary & 2 & 1.5 \\
Tertiary & 73 & 53.7 \\
Occupational status & 21 & 15.4 \\
Unemployed & 36 & 26.5 \\
Self-employed & 6 & 4.4 \\
Student & & \\
Farming & 109 & 80.1 \\
Place of Settlements & 27 & 19.9 \\
Camp & & \\
Host community &
\end{tabular}

\subsubsection{Data Collection Procedure from the Camp}

The ethical committee of Babcock University, Nigeria (BUHREC581/20) approved this research, in addition to the written permission obtained from the camp chairperson. The registry of IDAs was accessed through the camp chairperson, and the selection of potential participants was based on the established eligibility criteria, which included individuals aged 10 to 21 years who were internally displaced. Prior to conducting this study, we planned to use the WHO (1989) established cutoff point of 10-19 years of adolescent age. However, due to issues concerning the population and the experiences we encountered during data collection, which included (i) unequal gender distribution of the reference population and (ii) the fewer number of IDAs that met the study inclusion criteria of age 10-19 years old, we extended the age limit of the participants by including IDAs up to 21 years old so as to increase the number of participants. Nevertheless, Nader et al. (1993) recruited participants aged 8 to 21 in a similar study among Kuwaiti children and adolescents who were exposed to the Gulf War. To sum up, this process was deemed important for conducting our study because we recognize that such an adjustment will increase the number of potential participants, thus assisting in achieving the set purpose of the study. Participants who met the above criteria and accepted participation were invited for a meeting where the purpose and consent of the study was explained to them. After this, consent was gained from IDAs' parents or legal guardians for those who were minors and verbal assent was obtained from the IDAs themselves, whereas IDAs who were 18 years and above consented immediately on their own prior to the administration of the questionnaires. However, participants were duly informed about their freedom to withdraw from participation any time.

\subsubsection{Data Collection Procedure in the Host Community}

Participants living in the K-Vom host community were selected after verbal authorization was secured from the community leader for accessing the IDPs in their houses. Afterwards, each of the households were visited to identify potential participants based on the age eligibility. Once the IDAs were considered eligible, the purpose of the study was explained. Both consent and verbal assent were obtained. Then, they were informed about their freedom to withdraw their participation at any time. Moreover, before the questionnaires were administered, we ensured that they are comfortable with the study protocol. The questionnaire was prepared in English, but provision was also made if any IDAs had difficulties with accessing or understanding the questionnaire text; such individuals were supported by members of the research team by reading or explaining the questions when necessary. 


\subsection{Measures}

Post-traumatic stress disorder: The Harvard Trauma Questionnaire (HTQ-IV) was used to assess PTSD symptomology and to make an estimate of a PTSD diagnosis. The scale is believed to be sensitive to culture-specific PTSD symptomology (Mollica et al. 1992). The 16 items are divided into three subscales that correspond to the three main symptom groups of PTSD in the Diagnostic and Statistical Manuel of Mental Disorder (DSM-5), American Psychiatric Association (American Psychiatric Association (APA) 2013). The questions are measured on a five-point severity scale of $1-5$, which assesses how much a range of symptoms bothered participants in the past week (e.g., "recurrent thoughts or memories of the most hurtful or terrifying event"). The scores for each respondent were summed up and then divided by the total number of items. To estimate PTSD, a standard cutoff score of 2.5 (Mollica et al. 1992) was used as an indication of a high likelihood of PTSD. The HTQ for PTSD showed a high alpha $(\alpha=0.92)$ among young refugees (Elklit et al. 2012). In the current study, a Cronbach's alpha of 0.93 was obtained, indicating a high reliability of the scale.

Insomnia symptoms: To measure the insomnia symptoms, the Insomnia Severity Index (ISI) was used. The development of ISI is based on DSM-5. ISI is consistent with the diagnostic criteria for insomnia. The ISI seven-item measure was used to assess the three different insomnia classifications (nature, severity, and impact (Bastien et al. 2001; Morin 1993)). ISI has a five-point Likert scale rating of points, with 0 indicating "no problem" and 4 indicating "very severe problem". The scale items include questions like "How satisfied or dissatisfied are you with your current sleep pattern?", and its total score ranges from 0 to 28 . The total score implies the absence of insomnia (0-7), sub-threshold of insomnia (8-14), moderate level of insomnia (15-21), or severe insomnia (22-28). Some studies have reported adequate psychometric properties for the English version (Blais et al. 1997), and it has been previously validated within internally displaced populations (Basishvili et al. 2012). In addition, a Cronbach alpha of 0.83 has been reported within the adolescent population (Chung et al. 2011). Similarly, in the present study, a higher Cronbach's alpha of 0.85 was obtained.

Social support: The Crisis Support Scale (CSS) was used to measure social support because of its multidimensional feature of social support. CSS assesses whether people accesses the availability of emotional or practical things, especially when in crises (Joseph et al. 1992; Elklit et al. 2012). The seven-item version of CSS was used in this study, which has a seven-point Likert response format, with statements such as "Are people sympathetic and supportive at the present time?". A high score indicates higher levels of social support. A good internal consistency (CSS T1 $\alpha=0.70 ; \mathrm{T} 2 \alpha=0.80$ ) was reported by Elklit et al. (2012) in their study among young refugee populations. A Cronbach alpha of 0.84 was obtained in the present study.

\section{Data Analysis}

The analysis was conducted using Statistical Package for the Social Sciences (SPSS) version 24.0. A multivariate analysis of variance (MANOVA) was conducted to explore the main and interaction effects of gender and place of settlement on social support, insomnia, and PTSD symptoms. MANOVA is considered appropriate when there is more than one dependent variable in a single analysis. It can protect against type I errors that might occur if multiple ANOVAs have been conducted independently. The statistical assumptions for MANOVA were met, except for the assumptions of normality and two cases of multivariate outliers on perceived social support and post-traumatic stress disorder variables. However, in MANOVA, one of the common issues that researchers face is the violation of the assumption of normality (Finch and French 2013). Given the violation of some of the parametric assumptions, Pillai's trace test was used prior to the main analysis because it is the most powerful and robust to account for the departure from the normality assumption (Field 2009; Pillai 1955). Similarly, MANOVA can tolerate a few multivariate outliers found in this present study (Tabachnick and Fidell 1983). The results were interpreted with 
caution. First, the mean scores descriptive differences were analyzed, followed by two methods of MANOVA for determining the main and interaction effects of gender and place of settlement for each of the dependent variables (social support, PTSD symptoms, and insomnia). The graph presented in Figure 1 visualizes the mean differences for the significant interaction effects. Furthermore, extra analyses of the descriptive statistics, and the mediating effect of social support in the relationship between gender and PTSD, and gender and insomnia, respectively, were carried out but not reported (see Supplementary Materials, Figures S1, S2 and Table S1).

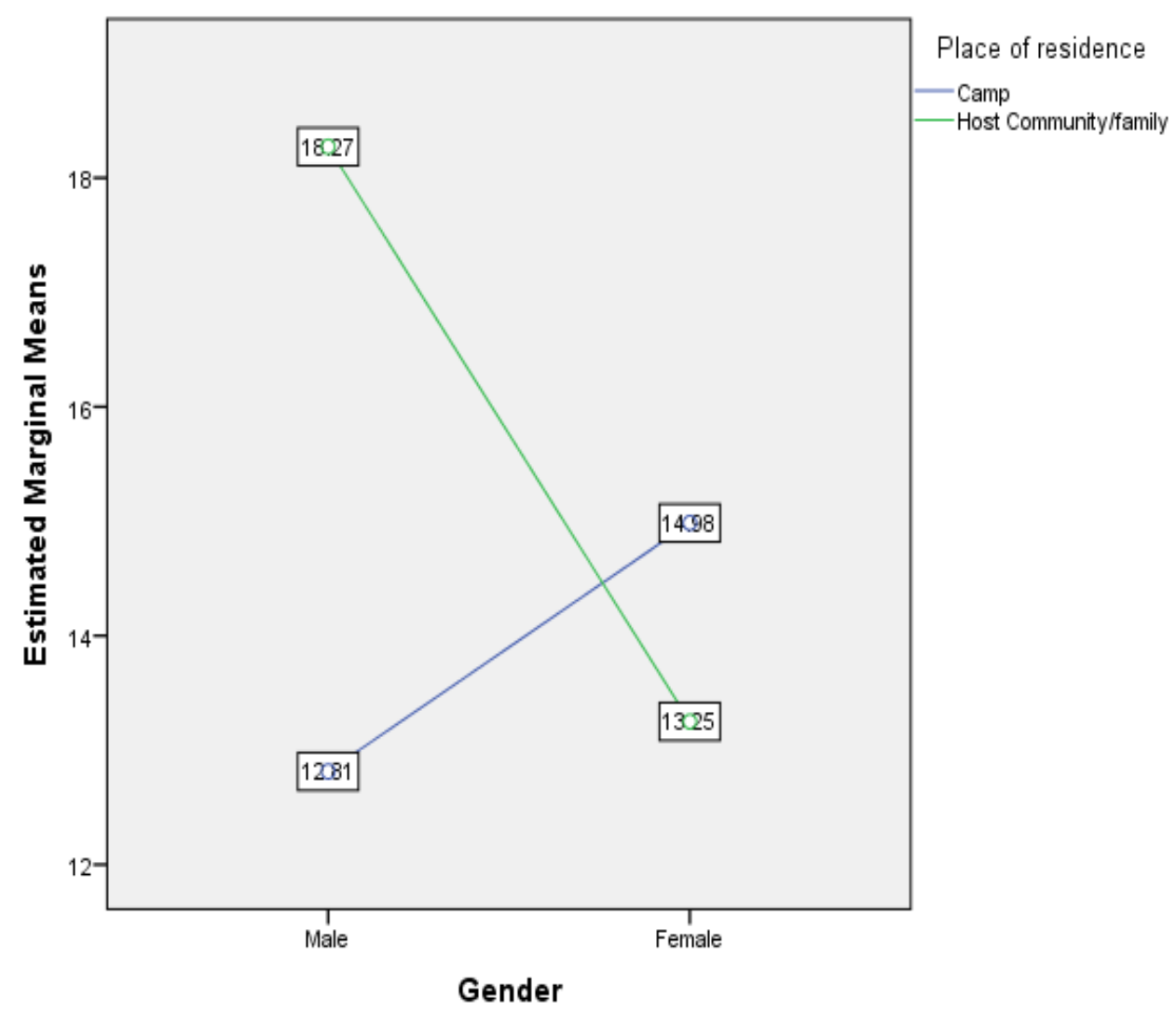

Figure 1. Interaction effect of gender and place of settlement/residence on insomnia.

\section{Results}

5.1. Mean Scores across Gender and Place of Settlement

Table 2 presents the mean scores for the dependent variables (perceived social support, post-traumatic stress disorder, and insomnia) across the independent variables (gender and place of settlement).

Table 2. Descriptive statistics showing mean scores across gender and place of settlement.

\begin{tabular}{cccc}
\hline Dependent Variable & Independent Variable & Mean & $S E$ \\
\hline PSS & Male & 31.06 & 1.30 \\
& Female & 31.32 & 1.07 \\
PTSD & Male & 48.26 & 1.82 \\
& Female & 45.91 & 1.50 \\
Insomnia & Male & 15.54 & 1.08 \\
& Female & 14.12 & 0.89 \\
PSS & Camp & 33.50 & 0.75 \\
& Community & 28.88 & 1.50 \\
PTSD & Camp & 45.70 & 1.05 \\
& Community & 48.47 & 2.12 \\
\hline
\end{tabular}


Table 2. Cont.

\begin{tabular}{cccc}
\hline Dependent Variable & Independent Variable & Mean & $S E$ \\
\hline Insomnia & Camp & 13.90 & 0.63 \\
& Community & 15.76 & 1.25 \\
PSS & Male in Camp & 32.67 & 1.17 \\
& Male in Community & 29.46 & 2.31 \\
& Female in Camp & 34.32 & 0.94 \\
PTSD & Female in Community & 28.31 & 1.92 \\
& Male in Camp & 45.88 & 1.64 \\
& Male in Community & 50.64 & 3.24 \\
& Female in Camp & 45.52 & 1.32 \\
& Female in Community & 46.31 & 2.69 \\
& Male in Camp & 12.81 & 0.97 \\
& Male in Community & 18.27 & 1.92 \\
& Female in Camp & 14.99 & 0.79 \\
& Female in Community & 13.25 & 1.60 \\
\hline
\end{tabular}

PSS—perceived social support; PTSD—posttraumatic stress disorder.

5.2. Main and Interaction Effects of Gender and Place of Settlement on Social Support, Insomnia, and PTSD Symptoms

The MANOVA results reveal that gender had no significant effect on perceived social support, PTSD, and insomnia. Conversely, place of settlement showed a significant effect on perceived social support $\left(\mathrm{F}(1.132)=7.552, p=0.007 ; \eta p^{2}=0.054\right)$, with participants living in a camp having a higher mean score (33.50) compared to participants in the community (mean score 28.88; see Table 2). Place of settlement had no significant effect on PTSD and insomnia. Furthermore, a significant interaction effect of gender and place of settlement on insomnia was observed $\left(\mathrm{F}(1.132)=6.623, p=0.011 ; \eta \mathrm{p}^{2}=0.048\right)$, with males living in the community having a higher (mean score 18.27) for insomnia (see Figure 1). However, no significant interaction effect of gender and place of settlement on perceived social support or PTSD symptoms was observed.

\section{Discussion}

This study investigated gender and place of settlement (camp versus non-camp) effects on perceived social support, insomnia, and PTSD symptoms. It also examined if there was a significant interaction effect between gender and place of residence (camp versus non-camp) on social support, insomnia, and PTSD symptoms.

\subsection{Gender Main Effects}

No statistically significant effect of gender was found on perceived social support, PTSD symptoms, and insomnia. In terms of the non-significant gender effect on PTSD, this finding is congruent with the results previously reported by Taha and Sijbrandij (2021) in Iraqi, and by Yasan et al. (2009) in Turkey, among IDPs. It is also consistent with the findings by Rothe et al. (2002) in the Cube, Elbedour et al. (2007) in Gaza, Ellis et al. (2008) in Somali, and the study of Mels et al. (2010) in the Eastern Region of Congo. Conversely, the present study did not support other similar studies, which reported gender differences regarding PTSD (Ainamani et al. 2020; Ditlevsen and Elklit 2010; Elklit et al. 2012; Frans et al. 2005; Johansen et al. 2007; Idemudia et al. 2013; Olff et al. 2007; Sheikh et al. 2016). However, Kunovich (1999) suggested that one of the possible reasons males and females differs in PTSD symptoms may be related to societal contexts and the ways gender roles have been affected. Thus, connecting this to the females in a patriarchal society like Nigeria, where gender subordination exists, there is likely to be a higher tendency for female IDAs to experience indelible traumas, adding to displacement vulnerability, which could possibly have a profoundly negative effect on females. For instance, in a population study in Nigeria by Ruth and Ijere (2018), it was found that females who reported poverty and were oppressed by the male gender also had more symptoms of PTSD. Further, female IDAs 
in Nigeria may be forced to take on new roles and responsibilities to ensure their own and their families' basic needs, and this may cause stress to their lives, which may in turn compound the raised risk of psychological problems. For instance, it has been shown that female risk factors for many mental health problems are associated with societal pressures and higher obligatory physical labor (WHO and Calouste Gulbenkian Foundation (WHO and CGF 2014)). In Nigeria culture, gender inequality is highly embedded, thus, no gender variation on PTSD symptoms was found in the present study. Therefore, it may be of further interest for future studies to assess whether cultural factors increase the risk of PTSD across gender, especially in displaced populations.

Furthermore, the present study shows no significant effect of gender on insomnia. This is comparable with the study of Kolakowsky-Hayner et al. (2021), who reported non-significant differences between males and females on insomnia. This is surprising as we anticipated that in a socially sanctioned culture like Nigeria, females might be more vulnerable to a higher rate of insomnia. For example, in a Nigerian study by Ogundele et al. (2017), females reported a higher consumption of insomnia medication compared to males. However, the present study contradicts that of Zhang and Wing (2006), whereby females reported to be more predisposed to insomnia, such that their insomnia was consistent and progressive across the age ranges. Likewise, our findings did not support the studies of Polyné et al. (2021) and Zeng et al. (2020), which showed higher significant levels of insomnia for females compared with their male counterparts. Nevertheless, a combination of factors is suggested to be responsible for contributing to gender disparity on insomnia (Mallampalli and Carter 2014). Therefore, to determine the disparity of gender on insomnia requires a robust assessment that considers other potential factors of the IDAs not investigated in the present study.

According to the results of the present study, no significant main effect of gender on perceived social support was found. This is congruent with the studies of Akiyama et al. (2013) and Betancourt et al. (2012). Equally, the present study's findings are in contrast with the study of Araya et al. (2007) among post-conflict displaced persons in Ethiopia, where males IDAs reported higher levels of perceived social support compared to females, similar to other similar studies where females reported higher social support compared to males (Llabre and Hadi 1997).

\subsection{Place of Settlement Main Effects}

No statistically significant effect of place of settlement was found on PTSD symptoms and insomnia. Nevertheless, there was a significant effect of place of settlement on perceived social support; IDAs who reside in camps had higher perceived social support than those living in the host community. This is in accordance with previous reports showing that IDPs in camps are twice as likely to be provided with assistance and protection compared to those in non-camp settings (IASC 1993). It is likely that IDAs outside camps have difficulties supporting themselves as they struggle to settle down and start a new life compared to IDAs in the camp settings, who may not be facing challenges such as paying for rent and buying food. Further, the present study suggests that IDAs living in the host community may be receiving assistance resources that do not resonate within their perceived needs, or that the received and perceived support in non-camp settings is intermediated by other factors such as stress and coping, although perceived support and received support appear to have different antecedent processes and thus are separable constructs with distinct issues for consideration in their usage. Similarly, perceived support implies an individual's potential access to social support, while received support denotes receipt of support resources. Additionally, Barrera (2000) suggest that received support is more likely to represent a situational factor, especially when sought or provided in response to stressful moments. 


\subsection{Interaction Effects}

There was a significant interaction effect of gender and place of settlement on insomnia, with male IDAs living in the host community showing a higher level of insomnia compared to the females within the host community and males and females in the camp. The higher level of insomnia reported by male IDAs in the host community could be linked to their difficulties in finding easy solutions to their daily needs on their own compared to their counterparts in the camp, where government and non-governmental organizations provide their basic needs. This finding has an implication for the need to understand IDA males who reside in non-camp settings better, including the nature of their challenges, the outcomes they desire, and the limitations they experience. Similarly, it is likely that the higher rate of insomnia symptoms as reported by male IDAs' living in the community may improve if they can find suitable resources support within the areas of their needs. However, further investigation is needed to ascertain if male IDAs in host community's vulnerability for insomnia was based on, the intermediation between their perceived areas of support needed and received support. Further, given that the present study found non-significant interaction effect of gender and place of settlement on social support and PTSD, we suggest that the effect of gender on social support and PTSD does not depend on the place of settlement.

\subsection{Limitations and Future Research Suggestions}

There are some limitations to be mentioned in this study. Firstly, based on the sample examined, the findings are restricted to the Nigerian context, we were unable to control for potential influencing factors such as traumatic experience and specific living conditions of the IDAs in camp and non-camp. Secondly, the IDAs sampled from non-camps were smaller compared to those sampled from the camp, due to this, the small cell sizes between the two samples limits their ability to confidently assert whether the MANOVA result is reliable. Thirdly, the social support measures used were based on the perceived support content; this limited our knowledge of the inter-dependence between perceived and received support. As such, the interpretation of these findings should be treated with caution. The strength of this study is that we included samples from IDAs in camps and those from non-camp settlements. Furthermore, this is a rare study as it highlights the interaction effects of gender and place of settlement on social support, insomnia and PTSD in conflict-displaced adolescents in Nigeria. There is a need for future research to explore the effect of place of settlement (camp and non-camp) on perceived and received social support of the IDAs. This is essential to identify specific needs that can help to promote resources and support across IDAs' place of settlement.

\section{Conclusions}

The findings of this study extend to related studies by identifying new evidence and focusing on the IDAs' place of settlement. It shows that IDAs in the camp setting perceived more social support compared to those living in the host community. Moreover, males living in the community had higher insomnia symptoms compared to their female counterparts, and to males and females in the camp. There is a need for future research to increase the understanding of the effect of place of settlement (camp and non-camp) on perceived and received social support of the IDAs. Our findings also merit further research to understand male IDAs who reside in non-camp settings better, including the nature of their challenges, the outcomes they desire, and the limitations they experience. The results from this study have practical implications for designing interventions for IDA mental health support in Nigeria. Specifically, gender and place of settlement should be considered to optimize mental health outcomes (insomnia). 
Supplementary Materials: The following are available online at https: / www.mdpi.com/article/ 10.3390/socsci10110428/s1, Figure S1: Model for Perceived social support as a mediator of the effect between gender and PTSD; Figure S2: Model for Perceived social support mediating the effect between gender and insomnia; Table S1: Mean and Standard Error Descriptive for effect of Sociodemographic characteristics on study dependent variables.

Author Contributions: Conceptualization, O.P.D. and J.D.; methodology, O.P.D. and J.D.; formal analysis, O.P.D., J.D. and I.Y.; investigation, O.P.D., J.D. and I.Y.; resources, O.P.D., J.D. and I.Y.; data curation, O.P.D.; writing —original draft preparation, O.P.D.; writing—review and editing, O.P.D., J.D. and I.Y.; visualization, O.P.D.; supervision, J.D.; project administration, O.P.D.; funding acquisition, O.P.D. All authors have read and agreed to the published version of the manuscript.

Funding: This research was funded by Total Elf Petroleum Nigeria under Grant No: DMDPHC.D /2015/049. The APC was funded by the authors.

Institutional Review Board Statement: The study was conducted according to the guidelines of the Declaration of Helsinki, and approved by the Health Research Ethics Committee of Babcock University (reference number BUHREC581/20; approved 27 January 2021).

Informed Consent Statement: Informed consent was obtained from all subjects involved in the study.

Data Availability Statement: The data presented in this study are openly available in Harvard Dataverse at https:/ / doi.org/10.7910/DVN/DIS955 (accessed on 10 July 2021).

Conflicts of Interest: The authors declare no conflict of interest.

\section{References}

Ainamani, Herbert E., Thomas Elbert, D. Kani Olema, and Tobias Hecker. 2020. Gender differences in response to war-related trauma and posttraumatic stress disorder-A study among the Congolese refugees in Uganda. BMC Psychiatry 20: 1-9. [CrossRef]

Akiyama, Takeshi, Thar Win, Cynthia Maung, Paw Ray, Kayako Sakisaka, Aya Tanabe, Jun Kobayashi, and Masamine Jimba. 2013. Mental health status among Burmese adolescent students living in boarding houses in Thailand: A cross-sectional study. Journal of Bio-Medical Central Public Health 13: 337. [CrossRef]

American Psychiatric Association (APA). 2013. Diagnostic and Statistical Manuel of Mental Disorders, 5th ed. Washington, DC and Arlington: American Psychiatric Association.

Araya, Mesfin, Jayanti Chotai, Ivan H. Komproe, and J. T. V. M. de Jong. 2007. Gender differences in traumatic life events, coping strategies, perceived social support and socio-demographics among post-conflict displaced persons in Ethiopia. Social Psychiatry and Psychiatric Epidemiology 42: 307-15. [CrossRef]

Ayazi, Touraj, Lars Lien, Arne Eide, Leslie Swartz, and Edward Hauff. 2014. Association between exposure to traumatic events and anxiety disorders in a post-conflict setting: A cross-sectional community study in South Sudan. BMC Psychiatry 14: 1-10. [CrossRef]

Barrera, M., Jr. 2000. Social support research in community psychology. In The Handbook of Community Psychology. Edited by Julian Rappaport and Edward Seidman. New York: Kluwer Academic/Plenum Publishers, pp. 215-45.

Basishvili, Tamar, Marine Eliozishvili, Lia Maisuradze, Nani Lortkipanidze, Nargiz Nachkebia, Tengiz Oniani, Irma Gvilia, and Nato Darchia. 2012. Insomnia in a displaced population is related to war-associated remembered stress. Stress Health 28 : 186-92. [CrossRef]

Bastien, Célyne H., Annie Vallières, and Charles M. Morin. 2001. Validation of the insomnia severity index (ISI) as an outcome measure for insomnia research. Sleep Medicine 2: 297-307. [CrossRef]

Betancourt, Theresa S., Carmal Salhi, Stephen Buka, Jennifer Leaning, Gillian Dunn, and Felton Earls. 2012. Connectedness, social support and internalizing emotional and behavioural problems in adolescents displaced by the Chechen conflict. National Institutes of Health 36: 635-55. [CrossRef]

Blais, France C., Linda Gendron, Véronique Mimeault, and Charles M. Morin. 1997. Evaluation de l'insomnie: Validation de trois questionnaires. Encephale 23: 447-53. [PubMed]

Bronstein, Israel, and Paul Montgomery. 2011. Psychological distress in refugee children: A systematic review. Clinical Child Family and Psychological Review 14: 44-56. [CrossRef] [PubMed]

Bruck, Dorothy, S. Atem Deng, Bichok Kot, and Michele Grossman. 2020. Sleep difficulties among South Sudanese former refugees settled in Australia. Transcultural Psychiatry 58: 172-86. [CrossRef]

Cairo, Javier B., Suparna Dutta, Haq Nawaz, Shahrukh Hashmi, Stanislav Kasl, and Edgar Bellido. 2010. The prevalence of posttraumatic stress disorder among adult earthquake survivors in Peru. Disaster Medicine and Public Health Preparedness 4: 39-46. [CrossRef]

Charak, Ruby, Cherie Armour, Ask Elklit, Disket Angmo, Jon D. Elhai, and Hans M. Koot. 2014. Factor structure of PTSD, and relation with gender in trauma survivors from India. European Journal of Psychotraumatology 5: 25547. [CrossRef] 
Chung, Ka-Fai, Katherine K. Kan, and Wing-Fai Yeung. 2011. Assessing insomnia in adolescents: Comparison of insomnia severity index, Athens insomnia scale and Sleep quality index. Sleep Medicine 12: 463-70. [CrossRef]

De Jong, Joop T. V. M., Ivan H. Komproe, Mark Van Ommeren, Mustafa El Masri, Mesfin Araya, Noureddine Khaled, Willem van de Put, and Daya Somasundaram. 2001. Lifetime events and posttraumatic stress disorder in 4 post conflict settings. Journal of American Medical Association 286: 555-62. [CrossRef]

DeLong, Hannah. 2012. Social Support in PTSD: An analysis of gender, race, and trauma type. Discussions 8: 1-3.

Ditlevsen, Daniel N., and Ask Elklit. 2010. The combined effect of gender and age on posttraumatic stress disorder: Do men and women show differences in the lifespan distribution of PTSD? Annals of General Psychiatry 9: 44-59. [CrossRef]

Elbedour, Salman, Anthony J. Onwuegbuzie, Jess Ghannam, Janine A. Whitcome, and F. Abu Hein. 2007. Post-traumatic stress disorder, depression, and anxiety among Gaza Strip adolescents in the wake of the second uprising (Intifada). Journal of Child Abuse and Neglect 31: 719-29. [CrossRef] [PubMed]

Elklit, Ask, Kjaer K. Ostergard, Mathias Lasgaard, and Sabina Palic. 2012. Social support, coping and posttraumatic stress symptoms in young refugees. Journal of Torture 22: 11-23. [PubMed]

Ellis, B. Heidi, Helen Z. MacDonald, Alisa K. Lincoln, and Howard J. Cabral. 2008. Mental health of Somali adolescent refugees: The role of trauma, stress, and perceived discrimination. Journal of Consulting Clinical Psychology 76: 184-93. [CrossRef] [PubMed]

Farhood, Laila F., and Hani Dimassi. 2012. Prevalence and predictors for posttraumatic stress disorder, depression and general health in a population from six villages in South Lebanon. Social Psychiatry Epidemiology 47: 639-49. [CrossRef]

Field, Andy. 2009. Discovering Statistics Using SPSS. London: Sage Publications.

Finch, Holmes, and Brian French. 2013. A Monte Carlo comparison of robust MANOVA test statistics. Journal of Modern Applied Statistical Methods 12: 35-81. [CrossRef]

Frans, Örjan, Per-Arne Rimmö, Lars Aberg, and Mats Fredrikson. 2005. Trauma exposure and post-traumatic stress disorder in the general population. Acta Psychiatry Scandinavian 111: 291-99. [CrossRef] [PubMed]

Hamid, Abdalla R. M. A., and Saif A. Musa. 2010. Mental health problems among internally displaced persons in Darfur. International Journal of Psychology 45: 278-85. [CrossRef]

IASC. 1993. Inter-Agency Standing Committee. In Proceedings of the 7th Working Group Meeting, Internally Displaced Persons Outside Camps: Achieving a More Equitable Humanitarian Response. Available online: https://reliefweb.int/report/world/ under-radar-internally-displaced-persons-non-camp-settings (accessed on 12 April 2021).

Idemudia, Erhabor S., John K. William, Klaus Boehnke, and Gail Wyatt. 2013. Gender differences in trauma and posttraumatic stress symptoms among displaced Zimbabweans in South Africa. Journal of Trauma Stress Disorder Treatment 2: 1340. [CrossRef]

IDMC. 2008. Internal displacement Monitoring Centre. Profiling Studies on IDPs in Urban Areas: Internal Displacement to Urban Areas: Khartoum, Sudan. September. Available online: http://sites.tufts.edu/feinstein/research/research-by-topic/internallydisplaced-persons?submit=Go (accessed on 20 May 2021).

IDMC. 2011. Internal displacement Monitoring Centre. Internal Displacement: Global Overview of Trends and Developments in 2010. Available online: www.internal-displacement.org/31FFB20A-37C4-4D48-85D1-4BC7B5C73277 (accessed on 19 June 2021).

IOM. 2018. International Organization for Migration. Displacement Tracking Matrix, Round 23 Report-June 2018. Available online: https:/ / reliefweb.int/sites/reliefweb.int/files/resources/Nigeria\%20-\%20.pdf (accessed on 12 April 2021).

IOM. 2021. International Organization for Migration. Displacement Tracking Matrix (DTM) of Nigeria North-East Zone Displacement Report Round 37 (August 2021). Available online: https://displacement.iom.int/system/tdf/reports/DTM\%20Report\%20 Round\%2037\%20\%20NE.pdf?file=1\&type=node\&id=12093 (accessed on 8 October 2021).

IRIN. 2013. Integrated Regional Information Network. With regard to Pakistan: How Best to Serve Pakistan's 750,000 IDPs? Available online: www.irinnews.org (accessed on 10 April 2021).

Jenchura, Emily C., Nancy A. Gonzales, Jenn-Yun Tein, and Linda J. Luecken. 2017. Gender and the Interplay of Source of Support and Peer Social Rejection on Internalizing Among Mexican American Youth. Journal of Youth and Adolescence 46: 787-800. [CrossRef]

Johansen, Venke A., Astrid K. Wahl, Dag E. Eilertsen, and Lars Weisaeth. 2007. Prevalence and predictors of post-traumatic stress disorder (PTSD) in physically injured victims of non-domestic violence. A longitudinal study. Social Psychiatry Epidemiology 42: 583-93. [CrossRef]

John, Prashantham B., Sushila Russell, and Paul S. S. Russell. 2007. The prevalence of posttraumatic stress disorder among children and adolescents affected by Tsunami disaster in Tamil Nadu. Disaster Management Response 5: 3-7. [CrossRef]

Joseph, Steve, Bernice Andrews, Ruth Williams, and William Yule. 1992. Crisis support and psychiatric symptomatology in adult survivors of the Jupiter cruise ship disaster. British Journal of Clinical Psychology 31: 63-73. [CrossRef]

Kamungi, Prisca. 2013. Municipal and IDPs Outside of Camps: The Case of Kenya's Integrated Displaced Persons, Brookings-LSE Project on Internal Displacement. Available online: http:/ / www.brookings.edu/research/reports/2013/05/kenya-displacementkamungi (accessed on 11 April 2021).

Kessler, Ronald C., Amanda Sonnega, Evelyn Bromet, Michael Hughes, and Christopher B. Nelson. 1995. Posttraumatic stress disorder in the national comorbidity survey. Archives of General Psychiatry 52: 1048-60. [CrossRef] [PubMed]

Kolakowsky-Hayner, Stephanie A., Yelena Goldin, Kristine Kingsley, Elisabet Alzueta, Juan C. Arango-Lasprilla, Paul B. Perrin, Fiona C. Baker, Daniela Ramos-Usuga, and Fofi Constantinidou. 2021. Psychosocial Impacts of the COVID-19 Quarantine: A Study of Gender Differences in 59 Countries. Medicina 57: 789. [CrossRef] [PubMed] 
Kubzansky, Laura D., Paula Bordelois, H. Jin Jun, Andrea L. Roberts, Magdalena Cerda, Noah Bluestone, and Karestan C. Koenen. 2014. The weight of traumatic stress: A prospective study of posttraumatic stress disorder symptoms and weight status in women. JAMA Psychiatry 71: 4451. [CrossRef]

Kumar, M. Suresh, Manoj V. Murhekar, Yvan Hutin, Thilakavathi Subramanian, Vidya Ramachandran, and Mohan D. Gupte. 2007. Prevalence of posttraumatic stress disorder in coastal fishing village in Tamil Nadu, India, after the December 2004 Tsunami. American Journal of Public Health 97: 99-101. [CrossRef]

Kunovich, Robert M. 1999. Civil war, social integration and mental health in Croatia. Journal of Health and Social Behavour 40: 323-43. [CrossRef]

Lee, Yu-Jin G., Jin Yong Jun, Yu Jin Lee, Juhyun Park, Soohyun Kim, So Hee Lee, So Young Yu, and Seog Ju Kim. 2016. Insomnia in North Korean refugees: Association with depression and post-traumatic stress symptoms. Psychiatry Investigation 13: 67-73. [CrossRef]

Lee, Chih-Yuan S., and Sara E. Goldstein. 2016. Loneliness, stress, and social support in young adulthood: Does the source of support matter? Journal of Youth and Adolescence 45: 568-80. [CrossRef]

Lies, July, Laura Jobson, Luis Mascaro, Theoni Whyman, and Sean P. A. Drummond. 2021. Postmigration stress and sleep disturbances mediate the relationship between trauma exposure and posttraumatic stress symptoms among Syrian and Iraqi refugees. Journal of Clinical Sleep Medicine 17: 479-89. [CrossRef] [PubMed]

Llabre, Maria M., and Foaziah Hadi. 1997. Social support and psychological distress in Kuwaiti boys and girls exposed to the gulf crisis. Journal of Clinical Child Psychology 26: 247-55. [CrossRef]

López-Torres Hidalgo, J., B. Navarro Bravo, I. Párraga Martínez, F. Andrés Pretel, J. Téllez Lapeira, and C. Boix Gras. 2012. Understanding insomnia in older adults. Intern Journal Geriatrics Psychiatry 27: 1086-93. [CrossRef] [PubMed]

Mallampalli, Monica P., and Christine L. Carter. 2014. Exploring sex and gender differences in sleep health: A society for women's health research report. Journal of Women's Health Larchmt 23: 553-62. [CrossRef]

Mels, Cind, Ilsa Derluyn, Eric Broekaert, and Yves Rosseel. 2010. The psychological impact of forced displacement and related risk factors on Eastern Congolese adolescents affected by war. Journal of Child Psychology and Psychiatry 5: 1096-104. [CrossRef] [PubMed]

Mollica, Richard F., Yael Caspi-Yavin, Paola Bollini, Toan Truong, Svang Tor, and James Lavelle. 1992. Harvard trauma questionnaire. Validating a cross-cultural instrument for measuring torture, trauma, and posttraumatic stress disorder in Indochinese refugees. Journal of Nervous and Mental Disorders 180: 111-16. [CrossRef]

Morin, Charles M. 1993. Insomnia: Psychological Assessments and Management. New York: The Guilford Press.

Nader, Kathleen O., Robert S. Pynoos, Lynn A. Fairbanks, Manal Al-Ajeel, and Abdulrahman Al-Asfour. 1993. A preliminary study of PTSD and grief among the children of Kuwait following the Gulf crisis. British Journal of Clinical Psychology 32: 407-16. [CrossRef]

Ogundele, Adefolakemi, Maroh Ighoroje, and Olukayode Abayomi. 2017. Insomnia and dysfunctional beliefs and attitudes about sleep among elderly persons in Abeokuta, Nigeria. International Journal of Clinical Psychiatry 5: 25-31. [CrossRef]

Olff, Miranda. 2017. Sex and gender differences in post-traumatic stress disorder: An update. European of Journal Psychotraumatology 8: 1-2. [CrossRef]

Olff, Miranda, Willie Langeland, Nel Draijer, and Berthold P. R. Gersons. 2007. Gender differences in posttraumatic stress disorder. Psychological Bulletin 133: 183-204. [CrossRef] [PubMed]

Pettus-Davis, Carrie, Christopher A. Veeh, Maxine Davis, and Stephen Tripodi. 2018. Gender Differences in Experiences of Social Support among Men and Women Releasing from Prison. Journal of Social and Personal Relationships 35: 1161-82. [CrossRef]

Pillai, Sreedharan K. C. 1955. Some new test criteria in multivariate analysis. Annual Mathematic Statistic 26: 117-21. [CrossRef]

Polyné, Nina C., Katherine E. Miller, Janeese Brownlow, and Philip R. Gehrman. 2021. Insomnia: Sex differences and age of onset in active duty Army soldiers. Sleep Health 7: 504-7. [CrossRef] [PubMed]

Raji, Shittu, Arinola F. Adekayaoja, E. Ayila Agaku, James Akujobi, and Ayinde Hamzat. 2021. North-eastern Nigeria: Assessing the response capacity of National Emergency Management Agency to the plights of internally displaced persons. Heliyon 7: e07274. [CrossRef]

Rothe, Eugenio M., John Lewis, Hector Castillo-Matos, Orestes Martinez, Ruben Busquets, and Igna Martinez. 2002. Posttraumatic stress disorder among Cuban children and adolescents after release from a refugee camp. Psychiatric Service 53: 970-76. [CrossRef]

Ruth, Abiola A., and Ignatius N. Ijere. 2018. Psycho-social traumatic events among women in Nigeria. Madridge Journal of AIDS 1: 17-28. [CrossRef]

Schraedley, Pamela K., Ian H. Gotlib, and Chris Hayward. 1999. Gender differences in correlates of depressive symptoms in adolescents. Journal of Adolescence Health 25: 98-108. [CrossRef]

Seelig, Amber D., Isabel G. Jacobson, Besa Smith, Tomoko I. Hooper, Edward J. Boyko, Gary D. Gackstetter, Philip Gehrman, Carol A. Macera, and Tyler C. Smith. 2010. Sleep patterns before, during, and after deployment to Iraq and Afghanistan. Sleep 33: 1615-22. [CrossRef] [PubMed]

Sheikh, Taiwo L., Abdulaziz Mohammed, Edwin Eseigbe, Tosin Adekeye, Folorunsho T. Nuhu, Modupe Lasisi, Abdulaziz Muhammad, Zainab T. Sulaiman, Aishatu A. Abdullateef, Nafisatu Hayyatudeen, and et al. 2016. Descriptive characterization of psychotrauma, psychological distress, and post-traumatic stress disorder among children and adolescent internally displaced persons in Kaduna, Nigeria. Front in Psychiatry 7: 179. [CrossRef] [PubMed] 
Steel, Zachary, Tien Chey, Derrick Silove, Claire Marnane, Richard A. Bryant, and Ommeren van Mark. 2009. Association of torture and other potentially traumatic events with mental health outcomes among populations exposed to mass conflict and displacement: A systematic review and meta-analysis. Journal of American Medical Association 302: 537-49. [CrossRef] [PubMed]

Stupar, Dusko, Dejan Stevanovic, Panos Vostanis, Olayinka Atilola, Paulo Moreira, Katerina Dodig-Curkovic, Tomislay Franic, Ana Doric, Nikolina Davidovic, Mohamad Avicenna, and et al. 2021. Posttraumatic stress disorder symptoms among trauma-exposed adolescents from low- and middle-income countries. Child Adolesc Psychiatry Ment Health 15: 1-10. [CrossRef] [PubMed]

Tabachnick, Barbara G., and Linda S. Fidell. 1983. Using Multivariate Statistics. New York: Harper and Row.

Taha, Perjan H., and Marit Sijbrandij. 2021. Gender Differences in Traumatic Experiences, PTSD, and Relevant Symptoms among the Iraqi Internally Displaced Persons. International Journal of Environmental Research and Public Health 18: 9779. [CrossRef]

Thabet, Abdelaziz M., and Sanaa S. Thabet. 2017. Stress, trauma and post-traumatic stress disorder among adolescents in the Gaza strip. Journal of Trauma Critical Care 1: 25-33.

Thoits, Peggy A. 2011. Mechanisms linking socialites and support to physical and mental health. Journal of Health Social Behavour 52: 145-61. [CrossRef] [PubMed]

Van Droogenbroeck, Filip, Bram Spruyt, and Gil Keppens. 2018. Gender differences in mental health problems among adolescents and the role of social support: Results from the Belgian health interview surveys 2008 and 2013. Bio-Medical Central Psychiatry 18: 6-10. [CrossRef]

WCRWC. 2006. Women's Commission for Refugee Women and Children. Displaced Women and Girls at Risk: Risk Factors, Protection Solutions and Resource Tools. Available online: https:/ /www.womensrefugeecommission.org/images/stories/WomRisk.pdf (accessed on 10 April 2021).

WHO. 1989. The Health of Youth. (Background Document A42/Technical Discussions/2), Geneva. Available online: https://apps. who.int/iris/handle/10665/172242 (accessed on 10 April 2021).

WHO. 2004. World Health Organization. Gender in Mental Health Research. Department of Gender, Women and Health (GWH) world Health Organization. Available online: http://apps.who.int/iris/bitstream/handle10665/43084/9241592532.pdf (accessed on 10 April 2021).

WHO and CGF. 2014. World Health Organization and Calouste Gulbenkian Foundation. In Social Determinants of Mental Health. Geneva: World Health Organization, Available online: http://apps.who.int/iris/bitstream/handle/10665/112828/9789241506809eng.pdf (accessed on 10 April 2021).

Yasan, Aziz, Gunay Saka, Mustafa Ozkan, and Meliksah Ertem. 2009. Trauma type, gender, and risk of PTSD in a region within an area of conflict. Journal of Trauma and Stress 22: 663-66. [CrossRef] [PubMed]

Yatham, Swetha, Shalini Sivathasan, Rosalia Yoon, Tricia L. da Silva, and Arun V. Ravindran. 2018. Depression, anxiety, and posttraumatic stress disorder among youth in low- and middle-income countries: A review of prevalence and treatment interventions. Asian J Psychiatr 38: 78-91. [CrossRef] [PubMed]

Zeng, Liang-Nan, Qian-Qian Zong, Yuan Yang, Ling Zhang, Yi-Fan Xiang, Chee H. Ng, Li-Gang Chen, and Yu-Tao Xiang. 2020. Gender Difference in the Prevalence of Insomnia: A Meta-Analysis of Observational Studies. Frontiers in Psychiatry 11: 1162. [CrossRef]

Zhang, Bin I., and Yun-Kwork Wing. 2006. Sex differences in insomnia: A meta-analysis. Journal of Sleep 29: 85-93. [CrossRef] [PubMed] 